\title{
LOGISTICA DE DISTRIBUICÁO DE ÁGUA POTÁVEL DA CIDADE DE PARACATU/MG: CARACTERIZAÇÃO DO SISTEMA DE GESTÃO
}

\author{
ARAÚJO, ANELISE \\ Graduanda em Engenharia civil \\ Centro Universitário Atenas \\ Minas Gerais; Brasil \\ avelaranelise@gmail.com

\section{LISBOA, IGOR} \\ Graduando em Engenharia civil \\ Centro Universitário Atenas \\ Minas Gerais; Brasil \\ igoraclisboa@outlook.com
}

\author{
RUAS, MATHEUS \\ Engenheiro Civil/Professor \\ Centro Universitário Atenas \\ Minas Gerais; Brasil \\ ruas91@gmail.com \\ ANTONIOLLI, PEDRO \\ Administrador/Professor \\ Universidade Metodista de Piracicaba \\ São Paulo; Brasil \\ pedro.antoniolli@unimep.br
}

\section{RESUMO}

O Brasil vive um cenário econômico marcado pela globalização, aliado à crescente alta populacional, o que gera um ambiente de competitividade. Assim, ao se considerar o sistema logístico de abastecimento de água, a existência de um plano de distribuição efetivo gera otimização neste processo, garantindo um fornecimento contínuo do produto. $O$ município de Paracatu está localizado no Noroeste do estado de Minas Gerais, e apresenta uma área territorial de $8.229,595 \mathrm{~km}^{2}$, com uma população estimada, no ano de 2015, de 92.386 habitantes (IBGE,2017). A NBR 12218:1994 arquiteta o sistema de distribuição de água potável como um elemento composto por tubulações e órgãos acessórios, destinada a disponibilizar o produto final aos usuários, de modo contínuo, em quantidade e pressão recomendadas (ABNT, 1994). Partindo de uma análise generalizada, o sistema de gestão do setor de saneamento básico do Brasil ainda é fundamentado na gestão da oferta, ou seja, a expansão do atendimento é realizada através da exploração de mananciais. Em 1997 foi fundado o Programa Nacional de Combate ao Desperdício de Água (PNCDA) do qual busca promover o uso racional da água nos sistemas de abastecimento. O índice de perdas de distribuição (IPD), analisa a possível perda nomeada reais ou físicas, que corresponde ao volume de água enviado para distribuição que não conclui o seu percurso total, podendo ser dissipado através de decorrentes fissuras, roturas e extravasamentos nas redes de distribuição. No ano de 2018, Paracatu/MG apresentou um porcentagem de IPD correspodneten a 40,03\% o que caracteriza a distribuição como um sistema "mau gerenciado", 2,21\% a mais comparado ao ano de 2016.

Palavras-chave: Abastecimento, Distribuição, Água potável, Perdas.

\begin{abstract}
Brazil is experiencing an economic scenario marked by globalization, allied to a growing population, which generates an environment of competitiveness. Thus, when considering the water supply logistics system, the existence of an effective distribution plan generates optimization in this process, ensuring a continuous supply of the product. The municipality of Paracatu is located in the northwest of the state of Minas Gerais, and has a territorial area of 8,229,595 $\mathrm{km}^{2}$, with an estimated population in 2015 of 92,386 inhabitants (IBGE, 2017). NBR 12218: 1994 architects the potable water distribution system as an element composed of pipes and accessory organs, intended to make the final product available to users continuously in recommended quantity and pressure (ABNT, 1994). Based on a general analysis, the management system of the sanitation sector in Brazil is still based on supply management, that is, the expansion of the service is performed through the exploitation of water sources. In 1997, the National Program to Combat Water Waste (PNCDA) was founded, which seeks to promote the rational use of water in water supply systems. The distribution loss index (IPD) analyzes the possible real or physical named loss, which corresponds to the volume of water sent for distribution that does not complete its full path, and can be dissipated through the resulting cracks, ruptures and overflows in the distribution networks. distribution. In 2018, Paracatu / MG presented a percentage of IPD corresponding to $40.03 \%$, which characterizes the distribution as a "badly managed" system, $2.21 \%$ more than in 2016 . Keywords: Supply, Distribution, Drinking water, Losses.
\end{abstract}




\section{INTRODUÇÃO}

No início da humanidade, as escolhas dos locais onde seriam implementadas as civilizações partiam do princípio de que houvesse lá, com abundância, os produtos principais para a sobrevivência. Alguns alimentos eram encontrados em certas regiões, sendo acessíveis em determinadas estações do ano. Consequentemente, nos primórdios, optava-se pela compra e estocagem do produto para consumo posterior. Contudo, devido à inexistência de sistemas desenvolvidos de transporte e armazenamento, o movimento das mercadorias limitava-se a aquilo que a pessoa conseguia fazer por suas próprias forças, e os bens perecíveis só podiam permanecer guardados por prazos muito curtos, normalmente obrigando as pessoas a viverem perto dos centros de produção, o que limitava o consumo a uma escassa gama de mercadorias.

A gestão de recursos hídricos no Brasil por um longo período de tempo esteve simplificada a somente avaliação quantitativa das reservas hídricas, especificadamente com foco na produção energética, efeito do modelo de gestão centralizado em atividade, que basicamente volta todos os olhares para o setor de planejamento estratégico com foco em hidroeletricidade.

Segundo Muñoz (2000), a gestão de recursos hídricos no Brasil por um longo período de tempo esteve simplificada a somente avaliação quantitativa das reservas hídricas, especificadamente com foco na produção energética, efeito do modelo de gestão centralizado em atividade, que basicamente volta todos os olhares para o setor de planejamento estratégico com foco em hidroeletricidade.

Julgando-se pelo elevado crescimento da civilização, a disponibilidade de regiões privilegiadas, onde haja existência de mananciais (utilizados para captação e distribuição de água), diminuiu consideravelmente. Como consequência, houve a necessidade de criação de um sistema de logística direcionado à captação, transporte, armazenagem e distribuição do produto (BALLOU, 2001).

À medida que os sistemas logísticos foram aperfeiçoados, o consumo e a produção passaram por uma separação geográfica. Algumas regiões se especializariam nas “commodities" para que sua produção seja realizada em melhores condições. Para Libânio (2004), com o aperfeiçoamento dos sistemas logísticos houve a necessidade de estudo e avaliação da distribuição dos setores impactados pelos recursos hídricos, e essas transformações produziram importantes efeitos, surgindo em alguns estados, inovadoras experiências de gestão de água. Como apresentado na Figura 1, o conjunto formado pela Gestão dos recursos hídricos, Saúde pública e Saneamento ambiental possui um importante valor para uma análise/conscientização do uso e distribuição de água. 


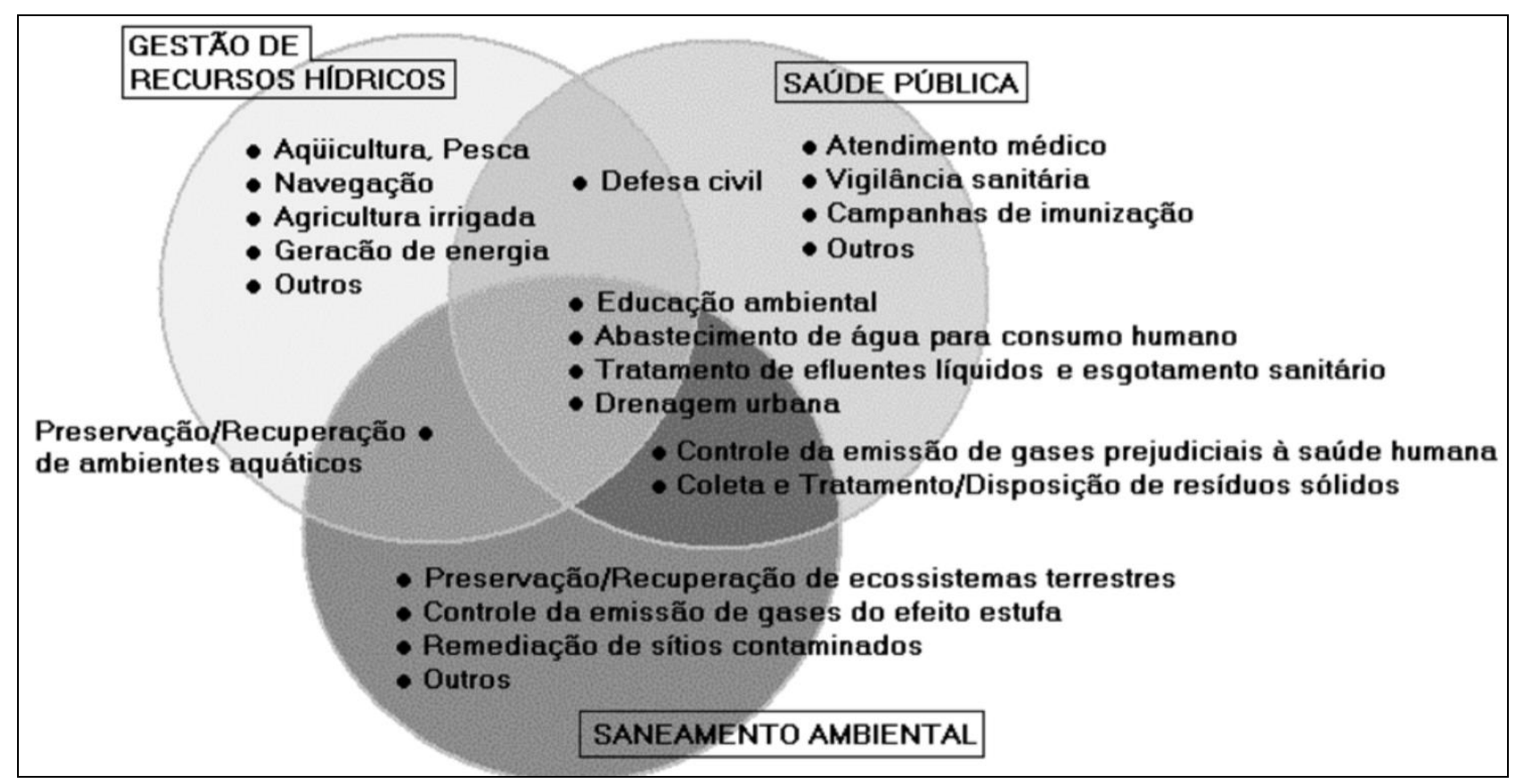

Figura 1 - Interfaces do saneamento ambiental com a gestão de recursos hídricos e com saúde pública.

O Brasil encontra-se em um cenário econômico marcado pela globalização, aliado à crescente alta populacional, o que gera um ambiente de competitividade no qual vivemos. Para Campos (2010), o novo modelo brasileiro de gestão das águas, inspirado no modelo francês, pressupõe a gestão descentralizada (o que significa possuir pontos de coleta de produto em diversos locais estratégicos para melhoria do abastecimento), participativa (todos as vertentes que englobam o sistema de abastecimento trabalham de forma direta ou indireta para o progresso) e integrada (com o intuito de tirar o Brasil da rota da escassez coloca-se a população a par do valor consciente a ser pago pela água para que haja uma gestão adequada), que deixa de privilegiar um plano que visava somente o setor elétrico, vigente por muito tempo no país.

Dentro deste contexto, ao se observar a organização, percebe-se que os seus recursos possuem importância, uma vez que se não estiverem em quantidade e perfil aderentes à demanda empresarial, pode haver desperdício, ou falta de um determinado produto. Sendo assim, considerando-se o sistema de logística empresarial e seu vasto campo de atuação, internamente e externamente à organização, este exerce função primordial no que diz respeito à criação, controle e cumprimento de metas. Um sistema de logística efetivo consiste em entregar o produto certo, na quantidade certa, no local certo, na hora certa, e na qualidade certa (BALLOU, 2001). Assim, ao se considerar o sistema logístico de abastecimento de água, a existência de um plano de distribuição efetivo gera otimização neste processo, garantindo um fornecimento contínuo do produto, gerando a satisfação plena do cliente, característica principal que toda organização deve almejar (ALMEIDA,2012).

O município de Paracatu está localizado no Noroeste do estado de Minas Gerais, e apresenta uma área territorial de 8.229,595 km², com uma população estimada, no ano de 2015, de 92.386 habitantes (IBGE,2017), conforme Figura 2. 


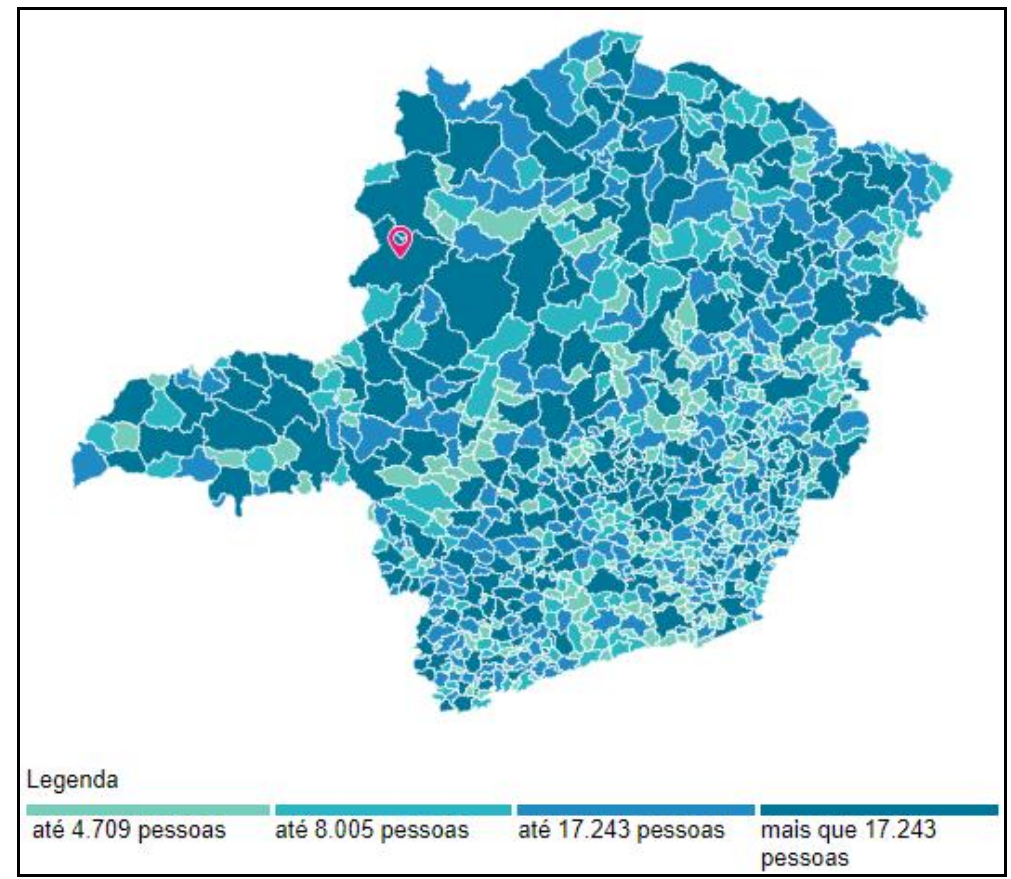

Figura 2 - Extensão territorial do município de Paracatu e sua população estimada.

A falta de água na cidade de Paracatu está ficando crescentemente complexa e preocupante. O município mineiro possui cerca de 91.027 habitantes (IBGE 2015), e está começando a sofrer com as baixas e desordenadas incidências de chuvas que estão prejudicando os mananciais, de onde são realizadas as coletas para abastecimento do município. No ano de 2017, a população vivenciou a maior crise hídrica da história, com um racionamento de água por cerca de aproximadamente três semanas. Como medida de fornecimento, foi divulgada pela Companhia de saneamento de Minas Gerais (COPASA) uma escala de abastecimento.

Uma das alternativas de abastecimento adotada pela concessionária de abastecimento da região (COPASA) foi de fornecer água potável através de caminhões pipa provindos da cidade vizinha, João Pinheiro. As discussões levantadas nas Câmaras Municipais das cidades de João Pinheiro e Paracatu, e pelos moradores/consumidores era se existiria algum tipo de plano de abastecimento emergencial para que não houvesse problemas futuros para ambas cidades.A COPASA, companhia responsável pelo saneamento básico da cidade de Paracatu, através de uma nota pública, ressaltou que os mananciais que abastecem a cidade encontravam-se abaixo do nível permitido para coleta e abastecimento. Como forma de conscientização, foram realizadas campanhas educativas incentivando o racionamento e uso consciente da água. A concessionária criou um plano de racionamento para adoção de rodízio no abastecimento, conforme Resolução 68/2015 da Agência Reguladora dos Serviços de Abastecimento de Água e Esgotamento Sanitário de Minas Gerais (ARSAE MG), até que seja aprovado o projeto que propõe a implantação de novas fontes de captação. A correta realização de um plano de logística de distribuição de água potável implica na qualidade de distribuição, pressão adequada e menores custos aos usuários, projetos estes que devem sofrer atualizações periódicas de acordo com o crescimento da demanda do produto 


\section{LOGÍSTICA DE DISTRIBUIÇÃO DE ÁGUA}

\subsection{Disponibilidade e demanda}

Fazendo-se uma análise generalizada, o sistema de gestão do setor de saneamento básico do Brasil ainda é fundamentado na gestão da oferta, ou seja, a expansão do atendimento é realizada através da exploração de mananciais, sejam eles distantes ou não. Se houver a disponibilidade de abastecimento, o mesmo será utilizado. Sendo assim, poderá acarretar elevados índices de perdas por vazamentos. O pouco interesse pelo plano efetivo do uso correto da água cria uma cultura nos domicílios de "bem material infinito", que gera desperdícios elevados. Apesar disso, a cada ano as cidades brasileiras se deparam com menos opções viáveis para extração da água para a expansão da oferta hídrica, principalmente nas regiões metropolitanas.

Segundo Faria et al. (2010), o conceito da gestão da demanda de água assemelha-se ao de Tecnologias Limpas, que nada mais é do que dar prioridade o exercício da conservação e do reuso, nos quais estão inclusos a otimização e a racionalização do uso, por intermédio da redução do consumo e da geração de efluentes e do reaproveitamento das águas. Ações como rapidez e agilidade em reparo de vazamentos representam, em grande parte das ocorrências, boas práticas operacionais, tais como:

a) Substituição/adequação de equipamentos;

b) Mudanças de procedimentos;

c) Mudanças de condições operacionais.

A gestão da demanda pode também ser demonstrada por intermédio de medidas estruturais e não estruturais. No que diz respeito aos sistemas públicos de abastecimento de água, as medidas estruturais versam sobre o uso de alternativas tecnológicas, de modo a promover a redução do consumo de água e melhoria do controle e operação, tal como das redes de distribuição de água. As medidas não estruturais baseiam-se em estímulos econômicos, leis, regulamentos e educação ambiental, de modo a transformar a conduta dos usuários das águas (VIEIRA; RIBEIRO, 2005).

Gleick (1996) aconselha um o volume de aproximadamente $50 \mathrm{~L} / \mathrm{hab}$.dia para atendimento às necessidades básicas (necessidades de higiene, bebida e limpeza). No entanto, o consumo nos domicílios não se limita somente às necessidades básicas, devendo ser contemplado o volume necessário para atender outros desejos da população, que não podem ser desconhecidos. Em contrapartida, a demanda dos sistemas de abastecimento de água possui outros usuários tais como, comércios e indústrias, que devem ser considerados.

\subsection{Logística de distribuição}

De acordo com Ballou (1993), parte das atividades da logística são consideradas primárias por elas contribuírem com a maior parcela do custo total, ou ainda são essenciais para a coordenação e o cumprimento da tarefa Logística. A logística é um sistema que está em constante desenvolvimento, entretanto o sistema logístico não era bem estruturado porque as mercadorias que as pessoas desejavam não eram produzidas no local onde elas gostariam de consumi-las, ou não eram acessíveis quando as desejavam. As atividades econômicas eram desenvolvidas com o intuito apenas de garantir as necessidades de sobrevivência das populações locais. Os produtos de consumo, alimentos ou bens materiais, 
eram geralmente produzidos em lugares específicos, e disponibilizados em quantidades suficientes, somente em determinadas épocas do ano. Não havia uma ampla variedade de produção.

Courtois et al. (2007), por sua vez, consideram que a cadeia de abastecimento é o processo global de satisfação dos clientes através da criação de uma cadeia de valores que integra, de forma otimizada, todos aos "autores" que estão na origem da execução de um produto ou de uma família de produtos. Baseado nos referidos autores, este é um processo que começa no "fornecedor do fornecedor" e termina no "cliente do cliente".

Estudos apresentados pela OMS (2014) abordam que o saneamento básico, um dos elementos do sistema de uma infraestrutura planejada, é definido como o conjunto de serviços, bases e instalações operacionais interligadas ao abastecimento de água, esgotamento sanitário, limpeza urbana e manejo de resíduos sólidos, e drenagem e manejo das águas pluviais urbanas (Lei nº 11.445/2007). Portanto, integrado ao conceito de obtermos um ambiente saudável e com condições favoráveis à habitação, a implementação geral de um Sistema de Saneamento Básico possibilita o desenvolvimento da sociedade como um todo em um ambiente favorável à sua melhora da qualidade de vida, impedindo enfermidades provindas de uma perda de qualidade de produto, de forma a contribuir com a evolução social e econômica da população.

Tsutyia (2006) retrata os componentes das etapas de distribuição do sistema de abastecimento de água (Figura 3), que são utilizados para a criação de um plano de Logística de abastecimento, e responsáveis pela coleta do produto até o fornecimento ao consumidor:
a) Manancial;
b) Captação;
c) Estações Elevatórias;
d) Adução;
e) Tratamento;
f) Reserva;
g) Distribuição. 


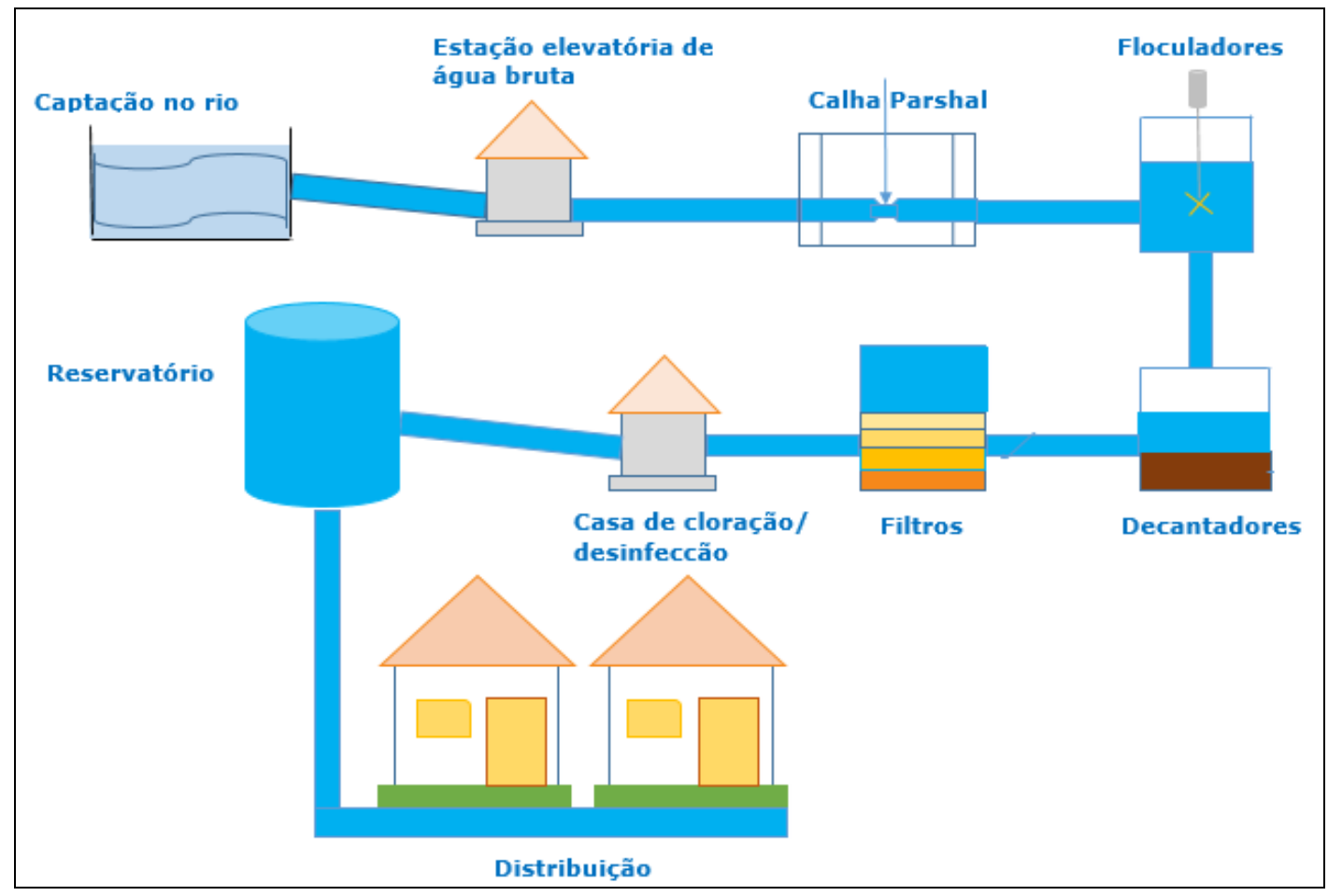

Figura 3 - Extensão territorial do município de Paracatu e sua população estimada.

\subsection{Gerenciamento de estoque para o abastecimento de água}

Administrar um sistema de estoque é garantir que ele esteja constantemente apto a atender a demanda dos clientes e dos utilizadores dos artigos em estocagem. Pode também, ser definido como sendo uma provisão de produtos destinados ao consumidor. As principais funções do estoque são: garantir o abastecimento de materiais à empresa, neutralizando os efeitos de demora ou atraso no fornecimento, sazonalidade e riscos de dificuldade no fornecimento e proporcionar economias na escala, através de compras em lotes econômicos, pela flexibilidade do processo produtivo e pela rapidez e eficiência no atendimento das necessidades do cliente. (ZERMATI, 2000).

Uma correta administração de estoque constitui em ações que admitem o administrador analisar se os mesmos estão sendo bem utilizados, bem localizados, bem manuseados e controlados. A gestão de estoque visa garantir a máxima disponibilidade de produto, com um montante de estoque mais baixo possível, pois se ter estoque é ter capital parado. Portanto, ter produtos no estoque sem ter um destino predeterminado ao mesmo significa não estar tendo nenhum retorno do investimento efetuado e, por outro lado, este capital investido poderia estar suprindo a urgência de outro segmento da empresa. Tal fenômeno cria a necessidade de existência de um plano de gerenciamento para projetar os níveis adequados, objetivando manter o equilíbrio entre estoque e consumo. Os níveis devem ser atualizados recorrentemente para impedir problemas gerados pelo crescimento do consumo ou vendas e alterações dos tempos de reposição. (MARTINS E ALT, 2003). 
Para as organizações da área da saúde, deve-se caracterizar o estoque como um mal necessário, pois o mesmo assegura a demanda em períodos de procura normal, tanto em períodos de demanda emergencial, ou seja, leva em consideração eventos sazonais (WANKE, 2004).

\section{GERENCIAMENTO DE RISCOS E PERDAS}

Em 1997 foi fundado o Programa Nacional de Combate ao Desperdício de Água (PNCDA) buscando promover o uso racional da água nos sistemas de abastecimento. Porém, o índice de desperdício ainda é alarmante. De acordo com Alegre et al. (2006) O International Water Association (IWA), caracteriza o fenômeno do desperdício de água como sendo o volume da diferença entre a água entregue ao sistema de abastecimento e os consumos autorizados, medidos, faturados ou não faturados, relativo aos usuários cadastrados e à própria companhia. Assim sendo, são subdivididas em duas ramificações: em reais (físicas) e aparentes (não físicas). Contudo, toda perda poderá existir em um sistema de abastecimento de água, cabe a análise do sistema mostrar se está ou não dentro dos limites aceitáveis.

A possível perda nomeada reais ou físicas corresponde ao volume de água enviado para distribuição que não conclui o seu percurso total, ou seja, não chega ao cliente, podendo ser dissipado através de decorrentes fissuras, roturas e extravasamentos nas redes de distribuição. Pesquisas apresentadas pelo Snis (2014) mostram que o excesso de pressão no sistema, qualidade dos materiais empregados, idade das tubulações, programas de gerenciamento/monitoramento de perdas e a mão-de-obra, entre outros fatores, são as principais motivações desse desperdício.

\subsection{Perdas Físicas}

Pesquisas apresentadas por Tabesh et al. (2009) salientam que as perdas físicas são características de corresponderem ao volume de água que é produzido pela concessionária porém não chega ao consumidor final, podendo ser geradas por problemas nas instalações, vazamentos nas adutoras, redes de distribuição, vazamento e transbordamento de reservatórios e por fim, fuga de válvulas e bombas.

Thornton et al. (2008) afirmam as causas para ocorrência desses vazamentos estão: na baixa qualidade da infraestrutura, da mão-de-obra e de materiais; na manipulação/estocagem inadequada de materiais; no processo de reaterro de valas inadequado; nas ondas de pressão ou transientes hidráulicos; na variação de pressão no sistema de distribuição, entre outras. Estes autores definiram as seguintes ações para reduzir tais perdas: rapidez e qualidade dos reparos, controle e detecção de vazamento, controle de pressão e de nível de reservatório e melhoria dos materiais e da manutenção, remanejamento e reabilitação das tubulações.

A quantidade de água perdida nos vazamentos é diretamente proporcional às características do orifício e das condições de operação do sistema (pressão), bem como sua duração, esta envolve três variáveis: conhecimento, localização e reparo (LAMBERT, 1998). O controle dos vazamentos é fundamentalmente uma ação inerente ao prestador do serviço. Contudo, é necessária uma boa relação deste com os usuários do serviço de modo que estes possam comunicar àqueles quando da existência de vazamento. Os vazamentos podem ocorrer em todos os subsistemas do abastecimento de água, sendo originados principalmente por vazamentos nas tubulações, nos ramais e nas estruturas, na limpeza do poço de 
sucção, na lavagem de filtros e descarga de lodo, extravasamentos, entre outros. As mais significativas são aquelas provenientes da rede de distribuição, tendo como causa as instalações e principalmente as pressões (PNCDA, 2003). As origens e magnitudes das perdas físicas por subsistema podem ser representadas esquematicamente, conforme o Quadro 1.

Quadro 1 - Perdas físicas.

\begin{tabular}{|c|c|c|c|}
\hline \multirow{6}{*}{ 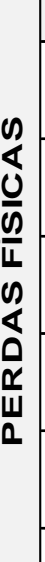 } & SUBSISTEMA & ORIGEM & MAGNITUDE \\
\hline & Adução da água bruta & $\begin{array}{l}\text { Vazamento nas tubulações; limpeza do poço de } \\
\text { sucção*. }\end{array}$ & $\begin{array}{l}\text { Variável, função do estado das tubulações e da } \\
\text { eficiência operacional }\end{array}$ \\
\hline & Tratamento & $\begin{array}{l}\text { Vazamento estruturais; Lavagem de filtros*; } \\
\text { Descarga de lodo*. }\end{array}$ & $\begin{array}{l}\text { Significativa, função do estado das instalações e } \\
\text { da eficiência operacional. }\end{array}$ \\
\hline & Reservação & $\begin{array}{l}\text { Vazamentos estruturais; Extravasamentos; } \\
\text { Limpeza*. }\end{array}$ & $\begin{array}{l}\text { Variável, função do estado das tubulações e da } \\
\text { eficiência operacional }\end{array}$ \\
\hline & Adução da água tratada & $\begin{array}{l}\text { Vazamentos nas tubulações; Limpeza do poço de } \\
\text { sucção*; Descarga*. }\end{array}$ & $\begin{array}{l}\text { Variável, função do estado das tubulações e da } \\
\text { eficiência operacional }\end{array}$ \\
\hline & Distribuição & $\begin{array}{l}\text { Vazamentos na rede; Vazamento nos ramais; } \\
\text { Descargas. }\end{array}$ & $\begin{array}{l}\text { Significativa, função do estado das instalações e } \\
\text { da eficiência operacional. }\end{array}$ \\
\hline
\end{tabular}

Fonte: Adaptado do PNCDA (2003)

\subsection{Perdas Aparentes}

As perdas aparentes se originam das ligações clandestinas ou não clandestinas, hidrômetros domiciliares defeituosos ou adulterados, falta de medição, fraudes nos hidrômetros e outros. Os fatores importantes na ocorrência das perdas aparentes: os erros de medição (macro e micromedição) e aqueles volumes destinados ao suprimento social (NEGRISOLLI, 2009).

Entretanto, segundo este mesmo autor, os volumes destinados ao suprimento social devem ser analisados cuidadosamente, visto que neste caso há consumo de água, inexistindo receita. Deste modo, a efetivação destas ligações não necessariamente irá reduzir o consumo de água, uma vez que em geral estas ligações são localizadas nas periferias das cidades, onde na maioria das vezes, tais ligações são atendidas por tarifas sociais. Isto não quer dizer que estes usuários apresentam consumo de modo a garantir a sustentabilidade dos recursos hídricos conforme observado por Garcia e Kiperstok (2010). A redução das perdas não físicas permite aumentar a receita tarifária, melhor eficiência dos serviços prestados e desempenho financeiro do prestador de serviços. Contribui indiretamente para a ampliação da oferta efetiva, uma vez que induz à redução de desperdícios por força da aplicação da tarifa aos volumes efetivamente consumidos.

Há no Brasil um predomínio de sistemas de abastecimento mistos (direto e indireto), aquele em que há pontos de consumo abastecidos diretamente pela rede pública e outros consumos com reservatório domiciliar (PNCDA, 2004). A inserção de reservatórios nos domicílios é decorrente da interrupção, escassez ou irregularidade do abastecimento. Entretanto, são comuns, nos sistemas indiretos, volumes escoados a pequenas vazões, não ser registrados. Isto irá ocorrer quando o nível do reservatório estiver próximo do limite superior e a torneira bóia estiver praticamente fechada, 
ou seja, quando a vazão de entrada for inferior à vazão mínima dos hidrômetros (GULARTE, 2005). "De maneira geral, os hidrômetros apresentam erros de medição mais elevados quando medem sob vazões muito pequenas comparativamente à sua vazão nominal” (PNCDA, 2004).

Miranda (2002) realizou uma comparação das perdas aparentes e das águas não faturadas entre países que utilizam reservatórios convencionais (caixas d'água) e aqueles onde o abastecimento é direto, não recomendado devido a estar passível a falta de abastecimento e concluiu que grande a ausência de fornecimento devido as perdas acarreta a carência do produto para alguns clientes. Pode-se afirmar então, que as perdas aparentes geram perdas financeiras, necessitando assim de ações administrativas e comerciais, visto que a água é consumida, contudo não faturada. As origens e magnitudes das perdas aparentes por subsistema podem ser representadas esquematicamente segundo o Quadro 02 a seguir.

Quadro 2 - Perdas aparentes no sistema de abastecimento de água: origem e magnitude.

\begin{tabular}{|c|c|}
\hline ORIC & IVIAC \\
\hline Liga & \multirow{6}{*}{$\begin{array}{l}\text { Podem ser significativas, } \\
\text { dependendo de: } \\
\text { procedimentos cadastrais e } \\
\text { de faturamento, manutenção } \\
\text { preventiva, adequação de } \\
\text { hidrômetros e } \\
\text { monitoramento do sistema. }\end{array}$} \\
\hline & \\
\hline Hid & \\
\hline Hidrô & \\
\hline iga & \\
\hline úmero de & \\
\hline
\end{tabular}

Fonte: Adaptado do PNCDA (2003)

Portanto, a redução da demanda de água dos sistemas de abastecimento de água envolve desde questões relativamente simples (fechar torneiras e reparar vazamentos visíveis nas ruas de forma rápida, ágil e efetiva) e ações mais complexas, como por exemplo, mudança de comportamento e padrão de consumo dos usuários que necessitam maior tempo para obtenção de resultados e continuidade.

Assim, as ações de controle das perdas aparentes bem como de redução do padrão de consumo, necessita de programas contínuos de educação ambiental para sensibilizar e mobilizar os usuários a mudar hábitos e costumes o que por sua vez demandam um tempo superior, quando comparado ao de controle dos vazamentos, para a obtenção dos resultados.

\subsection{Caracterização do sistema de abastecimento de Paracatu/MG}

Segundo Liemberger (2002) um dos principais problemas enfrentados pelo mundo é a perda de água durante a distribuição, tanto a real quanto a aparente. O Ministério das Cidades caracteriza sistemas de abastecimento adequados àqueles que apresentam Índice de Perdas na Distribuição (IPD) inferiores a 20\%. O IPD ajusta os valores de água distribuídos aos sistemas de abastecimento pelo volume consumido, calculando o desperdício. Segundo Gomes (2007) o IPD pode ser considerado também como parâmetro para mensurar a eficiência na administração de uma companhia de abastecimento, correspondendo:

- $\quad$ IPD $>40 \%$ - Sistema com mau gerenciamento;

- $40 \% \geq \mathrm{IPD} \leq 25 \%$ - Sistema com gerenciamento de nível intermediário;

- $\quad$ IPD $<25 \%$ - Sistema com bom gerenciamento. 
Documentos fornecidos pela empresa de distribuição de água e saneamento básico da cidade de Paracatu-MG, base do presente estudo, apresentou dados relativos à perda de produto durante os anos de 2016 a 2018 que apresentou resultados alarmantes (Quadro 3). Desde o ano de 2016 a porcentagem de perda distribuída vem em um crescente preocupante, chegando a atingir no ano de 2018 a marca superior a 40\% de IPD, podendo caracterizar o sistema como "mau gerenciado".

Quadro 3: Controle de perdas por abastecimento - 31/01/2019

\begin{tabular}{|c|c|c|c|c|c|c|}
\hline \multicolumn{7}{|c|}{ PERDA DE ÁGUA POR ABASTECIMENTO NA CIDADE DE PARACATU-MG - 31/01/2019 } \\
\hline \multirow{2}{*}{$\begin{array}{c}\text { PERÍODO } \\
\text { (MÊS/ANO) }\end{array}$} & \multirow{2}{*}{$\begin{array}{c}\text { VOLUME } \\
\text { DISTRIBUÍDO } \\
\text { TOTAL }\left(\mathrm{m}^{3}\right)\end{array}$} & \multicolumn{4}{|c|}{ VOLUME CONSUMIDO } & \multirow{2}{*}{$\begin{array}{c}\text { \% DE PERDA } \\
\text { DISTRIBUÍDA } \\
\text { COPASA }\end{array}$} \\
\hline & & TOTAL $\left(\mathrm{m}^{3}\right)$ & $\begin{array}{c}\text { \% PERDA } \\
\text { FATURADA }\end{array}$ & $\begin{array}{c}\text { VOLUME } \\
\text { FATURADO }\left(\mathrm{m}^{3}\right)\end{array}$ & $\begin{array}{c}\text { \% PERDA } \\
\text { DISTRIBUÍDA }\end{array}$ & \\
\hline $\mathrm{dez} / 16$ & 4945557 & 3492136 & 26,75 & 3622799 & 29,39 & 36,16 \\
\hline dez/17 & 4775987 & 3285379 & 30,44 & 3322012 & 31,21 & 37,82 \\
\hline $\mathrm{dez} / 18$ & 5161184 & 3248671 & 36,82 & 3260831 & 37,06 & 40,03 \\
\hline
\end{tabular}

Fonte: Elaboração própria.

\section{CONSIDERAÇÕES FINAIS}

O município por se tratar de uma cidade histórica possui muitas instalações em estado de manutenção e/ou substituição, com base nos resultados obtidos na presente pesquisa pode-se observar que o sistema de abastecimento de água potável da cidade de Paracatu/MG possui um grande percentual de perda de produto. Números coletados no ano de 2016 apresentam um nível considerável de perda de produto, o que gera preocupação geral entre os moradores e a administração do município, onde atingiu cerca de $36,16 \%$ de perda (perdas físicas e perdas aparentes).

No ano de 2017 a cidade do noroeste de minas enfrentou a maior crise hídrica já vista na história, diversos bairros ficaram sem a distribuição de água potável por até 20 dias consecutivos. Tal acontecimento acordou a população e o sistema de administração do município para realizar uma cobrança mais rígida a concessionária de saneamento de Minas Gerais no que diz respeito ao sistema de distribuição e manutenção do estoque, porém, os números continuaram a crescer. No mesmo ano o balanço de análise de perda de produto chegou a marca de $37,82 \%$ superando o ano anterior, e o pior de tudo, sem nenhuma medida cabível para a busca da melhoria do sistema. Em 2018 a Prefeitura Municipal de Paracatu exigiu um relatório que apresentasse balanço trienal evidenciando a real situação do sistema de abastecimento de água do município e exigiu também medidas alternativas para uma maior economia de água potável por parte dos consumidores, contudo, constatou-se que a porcentagem de perda de produto somente aumentava, chegando a marca de 40,03\% de perda no presente ano. As evidências apresentadas na pesquisa salientam a importância do monitoramento constante dos sistemas de distribuição de água do município, não somente a cidade de Paracatu/MG, mas também de inúmeras cidades brasileiras que sofrem com uma má gestão do abastecimento de água potável. Enquanto a água não for tratada como uma riqueza limitada, e não houver penalizações severas pelo desperdício do bem natural, as concessionárias não irão demonstrar a devida importância de se ter um sistema de gestão e distribuição de excelência.

\section{REFERÊNCIAS}

ALEGRE, H. et al. Performance indicators for water supply service - Second Edition, London: IWA Publishing, 2006.

ALMEIDA, C. M. P. R.; SCHUTER, M. R. Estratégia Logística. Curitiba: Iesde, 2012.

ASSOCIAÇÃO BRASILEIRA DE NORMAS TÉCNICAS. Projeto de estação de tratamento de água para abastecimento público. Rio de Janeiro, 1992. NBR 12.216

BALLOU, Ronald H. Logística empresarial; transportes, administração de materiais; distribuição física. Editora Atlas: São Paulo, 1993. 
BAlloU, R. H. Gerenciamento da Cadeia de Suprimento, Planejamento, Organização e Logística Empresarial. São Paulo: Bookman, 4ª Edição, 2001.

BRASIL. Lei $n^{\circ}$ 9.433, de 8 de janeiro de 1997. Institui a Política Nacional de Recursos Hídricos, cria o Sistema Nacional de Gerenciamento de Recursos Hídricos, regulamenta o inciso XIX do art. 21 da Constituição Federal, e altera o art. $1^{\text {o }}$ da Lei $\mathrm{n}^{\circ} 8.001$, de 13 de março de 1990, que modificou a Lei $\mathrm{n}^{\circ} 7.990$, de 28 de dezembro de 1989.

Courtois A., Pillet M. \& Martin-Bonnefous C. (2007), “Gestão da Produção - Para Uma Gestão Industrial Ágil, Creativa e Cooperante", $5^{\text {a }}$ edição, Lidel, Lisboa.

FARIA, Alessandra da Silva. KIPERSTOK, Asher. MEDEIROS, Yvonilde Dantas Pinto. BERETTA, Magda. Aproximação dos Conceitos de Gestão de Recursos Hídricos e Produção Limpa, Utilizando a Abordagem Gestão de Demanda. In.: I Congresso Baiano de Engenharia Sanitária e Ambiental - I COBESA. Salvador. 2010.

GARCIA, Ana. KIPERSTOK, Asher. Fatores Determinantes do Consumo de Água em Residências de Baixa Renda: Estudo de Caso. In: XXXII Congresso Interamericano de Ingenieria Sanitaria y Ambiental, AIDIS. Punta Cana. 2010

GLEICK, P. H. The changing water paradigm: a look at twenty-first century water resources development. Water International, v. 25, 2000, pp.127-138.

GOMES, H.P.; GARCIA, R.P.; REY, P.L.I. (Org.). Abastecimento de água: $O$ estado da arte e técnicas avançadas. João Pessoa, PB: Editora Universitária UFPB, 2007, 386p.

GULARTE, Cristiano Bittencourt. Um Estudo sobre a Submedição em Hidrômetros para Aplicação no Controle das Perdas Aparentes no Sistema de Abastecimento de Água de Blumenau. Dissertação (Mestrado). Universidade Federal de Santa Catarina. Pag. 138. 2005.

IBGE - Instituto Brasileiro de Geografia e Estatísticas. Indicadores de Desenvolvimento Sustentável: Brasil 2002. Rio de Janeiro: Diretoria de Geociências, (Estudos e Pesquisas, Informação Geográfica, n.2), 195p. 2002.

IBGE - Instituto Brasileiro de Geografia e Estatísticas. Censo Demográfico 2000. Características da população e dos domicílios - Resultados do universo. Rio de Janeiro, 520p. 2000.

LAMBERT, A.; MYERS, S.; TROW, S. Managing Water Leakage - Economic and Technical Issues. Financial Times, London, 1998.

LIBÂNIO, P. A. C. A Implementação da Política Nacional de Recursos Hídricos e sua Interface com Aspectos de Qualidade de Água: Implicações da Regulação de Recursos Hídricos sobre o Setor de Saneamento e no Controle da Poluição Hídrica. Versão preliminar da tese de doutorado apresentada para Exame de Qualificação. Belo Horizonte: Programa de Pós-Graduação em Saneamento, Meio Ambiente e Recursos Hídricos da UFMG, 2004.

LIEMBERGER, R. Do you know how misleading the use of wrong performance indicators can be? In. Seminário Internacional sobre programas de redução e controle de perdas em sistemas de abastecimento de água. Recife. 2002.

MARTINS, Petrônio Garcia, ALT,Paulo Renato Campos.Administração de Materiais. São Paulo: Editora Saraiva. $5^{\text {a }}$ tiragem, 2003.

MIRANDA, Ernani Ciríaco de. Avaliação de Perdas em Sistemas de Abastecimento de Água - Indicadores de Perdas e Metodologias para Análise de Confiabilidade. Dissertação (Mestrado). Departamento de Engenharia Civil e Ambiental. Universidade de Brasília. UNB - DF. 215 p. 2002.

MUÑOZ, H. R. Razões para um debate sobre as interfaces da gestão dos recursos hídricos no contexto da Lei de Águas de 1997. In: MUÑNZ, H. R. (Coord.) Interfaces da Gestão de Recursos Hídricos: Desafios da Lei de Águas em 1997. 2. ed. Brasília: Secretaria de Recursos Hídricos do Ministério do Meio Ambiente. p.13-30. 2000.

NEGRISOLLI, R. K. (2009). Análise de dados e indicadores de perdas em sistema de abastecimento de água Estudo de caso. Campo Grande. 191p. Dissertação (Mestrado). UFMS, Brasil. 2009. 
OMS:<https://nacoesunidas.org/oms-para-cada-dolar-investido-em-agua-e-saneamento-economiza-se-43-dolares-emsaude-global/>. Consultado em 04 de fevereiro de 2018.

PNCDA - Programa Nacional de Combate ao Desperdício de Água. Ministério do Planejamento e Orçamento Secretaria de Política Urbana. Documentos Técnicos de Apoio. Brasília, 1998.

PNCDA - Programa Nacional de Combate ao Desperdício de Água. Ministério do Planejamento e Orçamento Secretaria de Política Urbana. Documentos Técnicos de Apoio. Brasília, 2003.

PNCDA - Programa Nacional de Combate ao Desperdício de Água. Ministério do Planejamento e Orçamento Secretaria de Política Urbana. Documentos Técnicos de Apoio. Brasília, 2004.

SNIS - Sistema Nacional de Informação Sobre Saneamento. Disponível em: http://www.snis.gov.br/PaginaCarrega.php?EWRErterterTERTer=29. Acesso: 10 de abril de 2019.

TABESH, M. ASADIYANI YEKTA, A. H. BURROWS, R. An Integrated Model to Evaluate Losses in Water Distribution Systems. Water Resour Manage. V.23, p. 477-492. DOI 10.1007/s11269-008-9284-2. 2009.

THORNTON, Julian. STURM, Reinhard. KUNKEL, George. Water Loss Control. 2nd Ed. McGraw-Hill, New York, 632 p, 2008.

TSUTIYA, Milton Tomoyuki. Abastecimento de água. 4.ed. Departamento de Engenharia Hidráulica e Sanitária da Escola Politécnica da Universidade de São Paulo: São Paulo, 2006.

VIEIRA, Zédna M.C.L. RIBEIRO, Márcia M. R. Análise de Conflitos: Apoio à Decisão no Gerenciamento da Demanda Urbana de Água. Revista Brasileira de Recursos Hídricos, v. 134, n.. 3, p. 239-246. 2005.

WANKE, P. Tendências da gestão de estoques em organizações de saúde. ILOS - Instituto de Logística e Supply $\begin{array}{lllll}\text { Chain. Rio de } & \text { Janeiro, } & \text { Disponível em: }\end{array}$ http://www.ilos.com.br/web/index.php?option=com content\&task=view\&id=735\&Itemid=74>. Consultado em 25 de fevereiro de 2018.

ZERMATI, Pierre. A Gestão de Stocks.(2000). 5ª Edição. Lisboa: Presença, 2009. 